justicia y convivencia en paz, significa valorar el modelo "por sobre" el ser humano, colocar la economía al servicio de

la economía misma, como algo cíclico y centrípeto.

Consideramos que establecer, como lo hacemos, al derecho comoherramienta, equivale a correr el velo entre el uso que los incluídos hacen de él y la abstracción que pretenden desde el poder para los otros, vebigracia consolidar derechos individuales o personalísimos y exaltarlos,conlleva a que sus portadores - personas jurídicas-distintos diferentes en la forma de producción del derecho, convaliden el poder, acentuando mas aún en lo relacional la dominación que hoy sufre el ser humano -trabajador y consumidor-frente al sistema.

Pretender un derecho -herramienta, donde el Estado no sólo afiance su rol de árbitro, sin que reequilibre en lo relacional el vacío de poder de los de abajo para evitar la dispersión y consolidar la composición jurídica en red como alternativa causal y teleológica. Esto pensamos entonces que se logra contextuando el derecho a partir de las herramientas de los otros saberes, mostrar la desestructuración que se produce en esta posmodernidad y hacerlo desde lo pensable como una dialéctica contradictoria del ser, que enfrenta lo real y que se resiste, pues el hombre tiene fundamentalmente voluntad de vivir con dignidad y no de perdurar en la oscuridad siendo usado como mero recurso - en la producción de

acontecimientos económicos instrumento de títere estratégico en un consumismo, por el consumismo mismo, sin valor de cualificación de la vida social.

No podemos desperdiciar entonces las enseñanzas de la historeografía para mostrar que este proceso tiene similitudes com el comienzo de la historia de la modernidad y el asentamiento burgués; o la ideología, para mostrar al derecho como una ilusión, pero dentro de una realidad aludida, concreta, que merece ser revertida, etc.

En todo conjunto, hay un vacío y multiplicidades, el pensamiento epistemológico es una situación donde circulan todos los saberes, es una invitación a pensar el derecho en inercia y movimiento, porque el hombre está determinado por la utopía, pero también por la finitud del sistema y la estructura.

Este montaje de ideas, tensa el conocimiento jurídico, evita los mecanismos de ocultación, muestra la causa ausente, maneja como decía Heideger la identidad y la diferencia, provoca un universo donde el hombre y el derecho son lo relacional.

Hemos querido mostrar muy brevemente otro punto de esta posmodernidad y reflexionar sobre sus caminos históricos, con la humilde pretensión de contribuir y generar el pensamiento de contracorriente.

\title{
Contratos Bancários em Tempos Pós-modernos - Primeiras Reflexões ${ }^{1}$
}

\author{
Claudia Lima eMarques
}

Professora da Universidade Federal do Rio Grande do Sul, Brasil, Doutora em Direito pela Universidade de Heidelberg, Mestre pela Universidade de Tübingen, Alemanha e Presidente do BRASILCON - 1998-2000

\section{Introdução}

6

a análise da nova realidade contratual massificada, denomina mos um fenômeno que já se observa no mercado brasileiro atual, de contratos cativos de longa duração. Trata-se de uma série de novos contratos ou relações contratuais que utilizam os métodos de contratação de massa (através de contratos de adesão ou de condições gerais dos contratos), para fornecer serviços especiais no mercado, criando relações jurídicas com plexas, múltiplas e de longa duração, envolvendo uma cadeia de fornecedores organizados entre si e com uma característica determinante: a posição de "catividade" ou "dependência" dos clientes, consumido res.

Esta posição de dependência ou como aqui estamos denominando, de "catividade", só pode ser entendida no exame do contexto das relaçōes atuais, onde determinados serviços prestados no mercado asseguram (ou prometem) ao consumidor e sua família "status", "segurança", "crédito renovado", "escola ou formação universitária certa e qualificada", "moradia assegurada" ou mesmo "saúde" no futuro. A catividade há de ser entendida no contexto do mundo atual, de indução ao consumo de bens materiais e imateriais, de publicidade massiva e métodos agressivos de marketing, de graves e renovados riscos na vida em sociedade, e de grande insegurança quanto ao futuro. ${ }^{2}$

Um dos exemplos principais destes contratos cativos de longa duração são as novas relações banco-cliente e sobre estas quero agora concentrar minha análise, apresentando alguns aspectos novos, que podem ser encontrados também nas relações e contratos de uso de cartão de crédito, nos seguros em geral, nos serviços de organização e aproximação de interessados (como os

1. Trabalho realizado com extratos da terceira edição do livro da autora "Contratos no Código de Defesa do Consumidor", RT, 1998, apresentado no Congresso sobre Direito Bancário- IBDB, 6 de março 1998, São Paulo.

2. Assim nossa obra "Contratos no Código de Defesa do Consumidor", 2a Edição, São Paulo, Ed. RT, 1995, p. 57. 
exercidos pelas empresas de consórcios) nos serviços de transmissão de informações e de investimento de numerário alheio, de representação e compra de ações etc.

Outras denominações poderiam ter sido usadas, como as de "contratos múlti plos", "serviços contínuos", "relações contratuais triangulares", "contratos de serviços complexos de longa duração" etc. Alguns doutrinadores estão denominando estas relações contratuais cativas de con tratos "pós-modernos". 3

Anteriormente, preferimos não uti lizar esta expressão, uma vez que a maioria desses contratos são contratos conhecidos mesmo antes da revolução industrial (po exemplo, os contratos bancários) e não, es pecificamente, agora na fase industrial que vivemos ou, na fase pós-industrial que ca racterizaria a pós-modernidade européia. $\mathrm{O}$ novo aqui não é a espécie de contrato (se guro, por exemplo), mas a sua relevância no contexto atual, a sociedade de consumo atual beneficia e fomenta estes serviços, considerados, então, socialmente essenciais, a necessitar uma nova disciplina. Hoje após meus estudos de doutorado na Europa, considero que a análise dos reflexos da pós-modernidade no direito se impõe, mesmo que a denominação e a delimitação des te tema continue incerta e pouco científica. ${ }^{4}$

Neste trabalho quero destacar dois pontos, que me parecem importantes no mercado brasileiro atual de relações entre

bancos (múltiplos) e clientes consumidores stricto sensu: a mudança do modelo contratual, definida pela crise pós-moderna (I), pela valorização do tempo, do acesso ao crédito e da pressão nas relações (A) valorização da catividade no mercado e das imposições de boa-fé (B); assim como, analisar, a formação de uma nova noção de contrato, de relação contratual mais fluída, menos formal que parece estar sendo empregada nas relações múltiplas entre bancos e consumidores (II).

Sem o distanciamento histórico necessário para observar a "verdade" ou não destas teorias e idéias, podemos, apenas, tecer algumas considerações sobre o seu potencial identificador de alguns fenômenos contratuais de massa e reflexos no direito para ajudar a atuação dos profissionais do direito, especialmente a intervenção da magistratura, para reequilibrar estas relações per se desequilibradas.

\section{A crise pós-moderna e mudanças no modelo dos contratos bancários}

\section{A. A valorização da pressão, do crédito e do tempo}

Os chamados tempos pós-modernos são um desafio para o direito. ${ }^{5}$ Tempos de ceticismo quanto a capacidade da ciência do direito de dar respostas adequadas e gerais aos problemas que pertubam a socieda- de atual e modificam-se com uma velocidade assustadora. Tempos de valorização dos serviços, do lazer, do abstrato e do transitório, que acabam por decretar a insuficiência do modelo contratual tradicional do direito civil, que acabam por forçar a evolução dos conceitos do direito, a propor uma nova jurisprudência dos valores, uma nova visão dos princípios do direito civil, agora muito mais influenciada pelo direito públi co e pelo respeito aos direitos fundamentais dos cidadãos. Para alguns o pós-modernismo é uma crise de descontrução, ${ }^{6}$ de desdogmatização do direito ${ }^{7}$, para outros, é um fenômeno de pluralismo e relativismo cultural arrebatador a influenciar o direito, ${ }^{8}$ que aumenta a liberdade dos individuos, ${ }^{9}$ mas diminui o poder da crítica, da evolução his tórica ${ }^{10} \mathrm{e}$ da verdade no Direito, ${ }^{11}$ fenômeno contemporâneo à globalização ${ }^{12} \mathrm{e}$ a perda da individualidade moderna ${ }^{13}$, mas que assegura novos direitos individuais à diferença ${ }^{14}$ e aumenta o radicalismo das linhas tradicionais. $^{15}$

Nesta análise primeira sobre os contratos bancários em geral e sobre as relações juridicamente relevantes entre consumidores e instituições bancárias, financiadores e mesmo empresas administradoras de cartões de crédito, pareceu-me interessante incluir uma análise mais detalhada sobre a crise da teoria contratual oriunda dos novos movimentos sociais, filosóficos, culturais e econômicos, que estão sendo denominados de pós-modernos e seus eventuais reflexos no direito civil e nos métodos de contratação. Ao tratar dos contratos cativos de longa duração optamos por não utilizar esta terminologia "pós-moderna", justamente por sua insegurança e pelas críticas constantes que recebe, inclusive de autores como Habermas. ${ }^{16}$ Agora,

3. Veja especialmente Ghersi, Carlos Alberto, La Posmodernidad Jurídica - Una discussión abierta, Buenos Aires, Ed. Gowa, 1995 p. 13

4. Seguimos aqui o exemplo e a teoria criada pelo Prof. Dr. Dr.h.c. Erik Jayme nosso orientador de Doutorado, veja Jayme, Erik, Le droit internationale privé postmoderne, in Recueil des Cours de l'Académie de Droit internationale de la Haye, Kluwer, Doordrech 1995, II.

5. Assim Ghersi, La Posmodernidad, p. 14

6. Assim Carty, Anthony (Ed). Post-Modern Law, Edimburg, Univ. Press, 1990, p. viil: "Pos-modernism as a method of lege descontruction can as well be applied to the English and other legal orders."

7. Assim Boaventura de Souza Santos, Introdução a uma ciência pós-moderna, Ed. Graal, Rio, 1989, p. 17.

8. Assim, Jayme, p. 36 e seg. Como ensina Lopes, José Reinaldo de Lima, Direito e Transformação Social, Belo Horizonte, Ed. Nova Alvorada, 1997, p. 77, tanto o direito faz parte da cultura, quanto possui sua própria cultura:" ...0 sistema jurídico é cons tituído de uma "cultura". São as atitudes que fazem do sistema um todo, uma unidade, e que determinam o lugar dos aparelhos e das normas na sociedade glablmente considerada. A cultura juríica engloba tanto as atitudes, hábitos e treinamento dos profissionais quanto do cidadão comum" " Tal linha de pensamento possui tradicazo no Brasil, através do escola de Recite

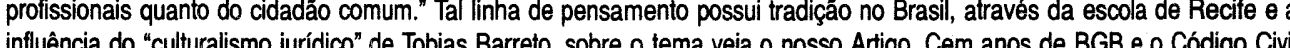
Influência do "culturalismo jurídico" de Tobias Barreto, sobre o tema veja o nosso Artigo, Cem anos de BGB e o Código Civil
Brasileiro, in: RT 741, p. 21 e seg. 9. Assim Friedman, Lawrence, The Republic of Choice, Cambridge, Harvard University Press, 1994, p. 61.

10. Assim Vatino, Gianni, O fim da modernidade, São Paulo, Martins Fontes, 1996, p. XII.

11. Assim Foucault, Michel, La verdad y las formas jurídicas, Ed. Gedisa, 4 R., Barcelona, 1996, p. 80 e seg.

12. Jayme, p. 36

13. Gehrsi, La Posmodernidad, p. 56, menciona relaçōes econômicas sem sujeito, relaçōes de grupos.

14. Jayme, p. 37.

15. Assim também Gellner, Ernest, Pós-modernismo, Razão e religião, Instituto Piaget, Lisboa, 1992, p. 11.

16. Como afirma Habermas, reconhecer, nomear ou denominar um fenômeno, como se faz com o pós-modernismo, significa se distanciar suficientemente deste $\theta$, mesmo, decretar o seu fim. Habermas não se considera pós-moderno, está comprometido com os ideais da modernidade, chega a ironizar a freqüente utilização na literatura atual desta denominação "pós", mas, por fim, reconhece a importância destes pensadores como sensiveis indicadores do "Zeitgeist", do pensamento e espirito atual a indicar uma mudança. Veja Habermas, Jürgen, Nachmetaphysisches Denken, Frankłurt, Ed. Suhrkamp, 1992, p. 12. 
porém, após a observação da jurisprudência e da doutrina brasileira não posso deixar de concluir pela atualidade do tema, a superar qualquer problema de simples denominação.

Vivemos um momento de mudanças, não só legislativa, mas política e social. Os europeus estão a denominar este momento de queda, rompimento ou ruptura (Umbruch), de fim de uma era e de início de algo novo, ainda não identificado, de pós-modernidade. Seria a crise da era moderna e de seus ideais concretizados na re. volução francesa, de liberdade, de igualdade e de fraternidade, ${ }^{17}$ que não se realizaram para todos, nem são hoje considerados realmente realizáveis, onde desconfia-se de sua força e suficiência para servir de paradigma à organização das sociedades democráticas atualmente em um capitalismo neo-liberal bastante agressivo, com fortes efeitos perversos e de exclusão social. ${ }^{18}$ Vivemos um momento de mudança também no estilo de vida, da acumulação de bens materias, passamos a acumulação de bens imateriais, dos contratos de dar, para os contratos de fazer, do modelo imediatista da compra e venda para um modelo duradouro da relação contratual, da substituição, da terceirização, das parcerias fluídas e das privatizações, de relações meramente

privadas para as relações particulares de iminente interesse social ou público.

Chame-se como desejar o momento atual de crise e de mudança, a sua realidade supera qualquer expectativa e seus reflexos no direito não podem mais ser negados. Na procura de quais seriam os reflexos desta crise "sociológica" no contrato, partiremos de uma análise mais ampla, elaborada por meu professor orientador de Doutorado, Erik Jayme dos reflexos da pósmodernidade no direito como ciência, para só então examiná-los enquanto sintomas da crise pós-industrial do direito dos contratos.

A realidade denominada pós-moderna ${ }^{19}$ é a realidade da pós-industrialização, do pós-fordismo, da tópica, do ceticismo quanto às ciências, quanto ao positivismo; ${ }^{20}$ época do caos, da multiciplicidade de culturas e formas, do direito à diferença, da "euforia do individualismo e do mercado", 21 da globalização e da volta ao tribal. É a realidade da substituição do Estado pelas emneo-liberalismo, de terceirizações, de comunicação irrestrita, de informatização e de um lação de bens não materiais, de desemprego massivo, ${ }^{22}$ de ceticismo sobre o geral, de

\section{Assim Carty, p.1.}

18. Veja por todos Tourraine, Alain, Uma Visão Crítica da Modernidade, in: Cadernos de Sociologia/UFRGS, vol. 5, p. 36 e seg.

19. Lyotard, Jean-François, Das postmoderne Wisse, Trad. Otto Persmann, Viena, Passagen Verlag, 1994, p.. 13: "Dieses Wort [postmodern] ist auf dem amerikanischen Kontinent, bei Soziologen und Kritikern gebräuchlich. Es bezeichnet den Zustand der Kustur nach den Transformationen, welche die Regeln der Spiele der Wissenschaft, der Literatur und der Kunste seit dem Ende Kultur nach den Transformationen, welch
des 19 Jahrhunderts getroffen haben."

20. Habermas, p. 35.

21. Assim Ghersi, La posmodernidad, p. 27: "No queda pues más que añadir, la posmodernidad es también la posmoralidad, es posolidaria, es sin duda le euforia del individualismo y el mercado, gobernados desde la tumba de Bentham por el nuevo perfil utilitarista, aliado al placer y a la felicidad consumista."

22. Assim a visão negativa de Ghersi sobre o pós-modernismo,Ghersi, La posmodernidad, p. 13 e ss. presas particulares, de privatizações, do neo-conservadorismo. Realidade de acumu- um individualismo necessário, da coexistência de muitas meta-narrativas simultâneas e contraditórias, da perda dos valores modernos, esculpidos pela revolução burguesa e substituídos por uma ética meramente discursiva e argumentativa, de legitimação pela linguagem, pelo consenso momentâneo e não mais pela lógica, pela razão ou somente pelos valores que apresenta. ${ }^{23} \hat{E}$ uma época de vazio, de individualismo na soluções ${ }^{24}$ e de insegurança jurídica, onde as antinomias são inevitáveis e a de-regula mentação do sistema convive com um pluralismo de fontes legislativas e uma for te internacionalidade das relações. ${ }^{25}$ É a condição pós-moderna que, com a pós-in dustrialização e a globalização das econo mias, já atinge a América Latina e tem reflexos importantes na ciência do direito É a crise do Estado do Bem-Estar Social. ${ }^{26}$

Segundo Erik Jayme ${ }^{27}$ as caracterís ticas, os elementos da cultura pós-moder na no direito seriam: o Pluralismo, Comunicação, a Narração, o que Jayme denomina de "le retour des sentiments", sen do o Leitmotive da pós-modernidade, a valorização dos direitos humanos. Para Jayme o Direito como parte da cultura dos povo muda com a crise da pós-modernidade.

O Pluralismo manifesta-se na multiplicidade de fontes legislativas a regu

\section{Kaufmann, Arthur, Grundprobleme der Rechstphilosophie, München, Beck, 1994, p. 224 e seg.}

24. Assim a visão negativa de Lipovetsky, Gilles, La era del vacío- Ensayos sobre el individualismo contemporáneo, Ed. Anagrama, Madrid, 1996, p. 7

25. Jayme, p. 36 e seg.

26. Assim Ghersi, Posmodernidad II, p.10.

27. Jayme, p. 36

28. Veja sobre pluralismo no direito, Friedman, The Republic, p. 11 e seg.

29. Kaufmann, Grundprobleme, p. 226 e Jayme, p. $246 s s$.

lar o mesmo fato, com a descodificação ou a implosão dos sistemas genéricos normativos (Zersplieterung), manifesta-se no pluralismo de sujeitos a proteger, por vezes difusos, como o grupo de consumidores ou os que se beneficiam da proteção meio ambiente, na pluralidade de agentes ativos de uma mesma relação, como os fornecedores que organizam-se em cadeia, e em relações extremamente despersonalizadas. ${ }^{28}$ Pluralismo também na filosofia aceita atualmente, onde o diálogo é que legitima o consenso, onde os valores e princípios têm sempre uma dupla função, o "double coding", e onde os valores são muitas vezes antinômicos. ${ }^{29}$ Pluralismo nos direitos as segurados, no direito à diferença e ao tratamento diferenciado dos diferentes ao privilégio dos "espaços de excelência".

A comunicação seria um valor máximo da pós-modernidade, a nova legitimação do direito, da Justiça estaria na comunicação e no revival da autonomia da vontade, associada a valorização extrema do tempo cação, de informação. Manifestar-se-ia na valorização do passar do tempo nas relações humanas, na valorização do eterno e do transitório, da necessidade de fixar/congelar momentós e ações para garantir a proteção dos mais fracos e dos grupos que a lei e do direito como instrumento de comuni-

Revista da Faculdade de Direito da UFRGS, v. 15, 1998 
quer privilegiar. A comunicação segundo muitos é o atual método de legitimação de todas as ciências, o discurso legitima, a informação cria mitos e transforma-se em verdade, tudo jogos de palavras (Sprachspiele).$^{30}$ Assim a nova ética e filosofia são discursivas ${ }^{31}$, assim o consentimento do indivíduo para ser legitimador é só aquele informado e esclarecido. ${ }^{32}$ Comunicação é também internacionalidade das relações jurídicas e a re-valorização do direito internacional privado e das técnicas de harmonização e unificação das leis. ${ }^{33}$

O elemento da narração origina-se na comunicação, é a conseqüência deste impulso de contato, de informação que invade a filosofia do direito e as próprias normas legais. Haveria, segundo Jayme, um novo método de elaborar normas legais, não normas para regular condutas, mas normas que narram seus objetivos, seus princípios, suas finalidades, positivando os objetivos do legislador no micro-sistema de forma a auxiliar na interpretação teleológica e no efeito útil das normas. ${ }^{34} \mathrm{O}$ método tradicional de elaborar normas que impunham condutas teria sido superado, pois estas não mais asseguram que os objetivos propostos serão alcançados, assim o legislador passa a esclarecer seu próprio objetivo (ratio legis),

ajudando e fixando a interpretação da norma no futuro, como normas narrativas, que iluminam a interpretação segundo Jayme ${ }^{35}$, mesmo que não cogentes, ou normas-objetivo, segundo o jus-filódofo brasileiro, Eros Roberto Grau. ${ }^{36}$

O que Jayme denomina "retour des sentiments" é, de um lado, a volta de uma certa "emocionalidade" no discurso jurídico, de outro lado é o impoderável, a procura de novos elementos sociais, ideológicos e/ou de fora do sistema, que passam a influir a argumentação e as decisões jurídicas, criando forte insegurança e imprevisibilidade quanto a solução a ser efetivamente encontrada. ${ }^{37} \mathrm{O}$ último elemento, verdadeiro Leitmotive destacado por Jayme é um revival dos direitos humanos, como novos e únicos valores seguros a utilizar neste caos legislativo e desregulador, de múltiplas codificações e microssistemas, de leis especiais privilegiadoras e de leis gerais ultrapassadas, de soft law e da procura de uma equidade cada vez mais discursiva do que real.

Esta crise da pós-modernidade é em verdade uma mudança na maneira de pensar o direito, um certo apatismo e imobilismo em relação às novidades, aos novos desafios e uma desconcertante crise

\section{Veja Lyotard, p. 87 e seg.}

31. Kaufmann, Grundprobleme, p. 213.

32. Charbin, Nicole, "Le contrat de consommation de crédit et l'autonomie de la volontée", LGDJ, Paris, 1988, Bibliothèque de Droit Privé, Tome CXCIX, p. 7.

33. Jayme, pg,. 247.

34. A definição de normas narrativas é de Jayme, Erik, Narrative Normen im internationalen Privat- und Verfahrensrecht, Mohr: Tübingen, 1993, p. 16. no Brasil veja os ensinamentos de Eros Roberto Grau.

35. Jayme, Narrative Normen, p. 16.

36. Grau, Eros Roberto, Direito, Conceitos e Normas, São Paulo,Ed. RT, 1988, p. 130 e seg.

37. Jayme, p. 261 e seg. de ideiais e de valores, que também tem influência no direito contratual deste final de século. Se assim podemos afirmar, os estudos sobre as mudanças na pósmodernidade, exista ela ou não, como momento histórico, acabaram por realçar ou espelhar os que já acontecera: a transformação o modelo contratual face aos limites do modelo contratual do século XIX. Do modelo estático da compra e venda, de um dar, passamos para um modelo dinâmico, complexo, reiterado e de fazeres de longa duração, como nos contratos de serviços e nos aqui estudados contratos cativos. Passamos de um contrato bilateral e comutativo, para o modelo de um contrato múltiplo, triangular ou plúrimo, onde nos polos encontram-se uma variada gama de sujeitos, como o fornecedor direto e a cadeia de fornecedores indiretos e sujeitos protegidos, como o consumidor-contratante, o consumidor stricto sensu e os consumidores equiparados; um contrato muitas vezes aleatório e se não, um contrato de fictamente-comutativo, pois o importante passa a ser o nexo das prestações e seu equilibrio (symalagma), não a prestação em si, mas seus anexos, sua qualidade, a informação que a acompanha, o status que assegura, a rapidez e a segurança quanto ao seu prestar.

Do contrato com regime geral e único, passamos para o contrato com regime jurídico plúrimo, tendo em vista a aplicação de uma série de leis especiais e gerais à mesma relação contratual em seus mais diversos aspectos. Este conviver de normas de diversas hierarquias e finalidades traz consigo o problema da solução de antinomias, mas do que a segura teoria da revogação expressa, hoje quase não mais usada. Onde há Zersplitterung, onde houve uma auto-implosão das grandes codificações e o aparecimento de vários micro-sistemas, as antinomias são inevitáveis e os princípios constitucionais, por vezes, mesmo eles contraditórios.

No novo modelo contratual há uma revalorização da palavra empregada e do risco profissional, aliada a uma grande censura intervencionista do. Estado quanto ao conteúdo do contrato, é um acompanhar mais atento para o desenvolvimento da prestação, um valorizar da informação e da confiança despertada. Alguns denominanm de renascimento da autonomia da vontade protegida. $O$ esforço deve ser agora para garantir uma proteção da vontade dos mais fracos, como-os consumidores. Garantir uma autonomia real da vontade do contratante mais fraco, uma vontade protegida pelo direito, vontade liberta das pressões e dos desejos impostos pela publicidade e por outros métodos agressivos de venda. Esta "nova autonomia" foi denominada por Nicole Charbin , em sua Tese de doutorado de 1988 de vontade racional ("volonté rationnelle"). ${ }^{38}$ A denominação parece-me feliz, pois indica a importância dos novos direitos dos consumidores: o direito à informação, o direito à reflexão e ao eventual arrepedimento como forma de proteção. Os métodos de venda mudaram e estão cada vez mais agrassivos, emocionais e apelativos, os desejos dos consumidores aprimoraramse e o consumismo não é mais um fenôme-

38. Charbin, p. 216 
no isolado, assim está cada vez mais dificil alcançar esta vontade realmente refletida ou "racional" como prefere Charbin.

A Tese de Charbin é um exemplo de teoria pós-moderna, pois tenta criar um double coding, mudando o sentido exatamente do dogma mais tradicional da teoria contratual: a autonomia de vontade. Agora, quer Charbin frisar a autonomia do outro, do mais fraco, do consumidor; sendo assim a expressão autonomia ganha um novo perfil, uma dupla significação e nunca mais poderá ser apenas (e unilateralmente) entendida como "autonomia do mais forte", do comerciante, do profissional. Assim também frisa o Juiz Schimasky da Corte Federal Alemã, em um recente Artigo de doutrina sobre a autonomia de vontade e os contratos bancários, que a liberdade contratual é uma norma de proteção (constitucional) de pessoas e a Corte sempre tentou proteger esta liberdade. "Entretanto não podemos proteger a liberdade contratual daquele que quer justamente reduzir, limitar ou mesmo excluir a liberdade contratual da outra parte. Liberdade é sempre a liberdade do outro." O magistrado da mais alta corte civil da Alemanha destaca ainda que o contrato é "por essência bilateral, a liberdade contratual é portanto indivisivel, ela significa a liberdade dos dois e não somente a liberdade do contratante mais forte." 39

O Professor da Universidade de Heidelberg, Erik Jayme, considerou o contrato de time-sharing ou de multipropriedade como o modelo de contrato da época pós-moderna. ${ }^{40} \mathrm{O}$ timesharing pode ser definido como um contrato múltiplo e complexo, visando o uso habitacional de um imóvel, de um complexo de imóveis, assim como dos serviços conexos a esta fruição, tudo por certo tempo a cada período de um ano. É paradigmático, pois possui uma série de características que podem ser classificadas como pós-modernas, a começar por seu objeto que é o lazer temporário, o uso de um imóvel em uma área turística e serviços conexos, por uma semana ou duas a cada ano. ${ }^{41}$ Também há que se destacar a natureza dos direitos assegurados aos consumidores, direitos múltiplos, mas nem todos de natureza real, já que a multipropriedade no mais das vezes não transfere e nem envolve direitos de propriedade, só direitos reais de uso. Estes direitos limitados de uso aliados a grande quantidade de serviços anexos prestados podem mesmo permitir tipificar este contrato como preponderantemente um contrato de fornecimento de serviços. Outra característica importante é a multiplicidade de agentes que envolvem este fornecimento de serviços e a fruição dos direitos de uso assegurados pelo contrato de time-sharing, desde o organizador (o incorporador ou verdadeiro proprietário do imóvel e do complexo turístico), o simples vendedor, o verdadeiro proprietário, o administrador do imóvel e do complexo de turismo, os fornecedores diretos da alimentação, de passeios etc. É muitas vezes um
39. Schimansky, Hebert, Bankvertragsrecht und Privatautonomie, in: WM- Zeitschrift für Wirtschafts- und Bankrecht (Frankfurt), Nr. 11, 18.03.95, p. 462 e 463

40. Jayme, p. 247

41. Veja Martinek, Michael, Moderne Vertragstypen, Tomo III,Munique: Beck, 1993 p. 268.

Revista da Faculdade de Direito da UFRGS, v. 15, 1998 contrato "sem fronteiras" ou internacional, pois as áreas e complexos turísticos muitas vezes localizam-se em outro país que o de domicílio ou nacionalidade do consumidor e a participação em "Circulos de Trocas Internacionais" torna possível que a fruição do direito de uso temporário dê-se em qualquer país. ${ }^{42}$

Como se pode observar, os valores ou elementos da pós-modernidade são fluídos, os estudos jurídicos ainda incipientes e, se em um momento permitem a criação de teorias como a de Charbin e pregam a revalorização dos direitos humanos, no próximo, a revalorização da vontade leva a conclusões incoerentes, como a da deslegitimação do Judiciário para resolver lides de consumo, pois a arbitragem, a mediação ou outros métodos alternativos de solução de controvérsias seria mais rápida ou "legitima", sem importar-se com a perpetuação do desequilíbrio ou a imparcialidade do árbitro.

Sendo assim, em tempos pós-modernos é necessário uma visão crítica do direito tradicional, é necessária uma reação da ciência do direito, impondo uma nova valorização dos princípios, dos valores de Justiça e equidade e, principalmente no direito civil, do princípio da boa-fé objetiva, como paradigma limitador da autonomia de vontade. Caso contrário, o próprio direito brasileiro ao privilegiar os mais fortes levará à opressão e exclusão dos mais fracos na sociedade. A crise atual leva a pensar na necessidade de proteção da vontade do

\section{Veja, por todos, a obra de Tepedino, Gustavo, Multipropriedade Imobiliária, Saraiva, São Paulo, 1993, p. 7 e seg}

43. Veja neste sentido nosso artigo, Contratos de Time-Sharing e a proteção dos consumidores: Crítica ao direito civil em tempos

pós-modernos, Revista Direito do Consumidor, vol. 22, pg. 65. consumidor, como ideal utópico remanescente da meta-narrativa da modernidade de tratamento desigual aos desiguais. É tempo de alterar o ponto de concentração do direito civil e pensar no grupo que recebe as declarações, na confiança despertada pela atuação profissional dos fornecedores e não só em estabelecer normas que privilegiam aquele que declara, aquele que redige os seus métodos de marketing agressivos ou emotivos de venda. No novo direito contratual, pois, a liberdade contratual do profissional não deve ser a única a merecer proteção jurídica, pois sua posição de poder (Machtposition) nas tratativas contratuais é clara e intrínseca aos métodos contratuais atuais, mas, sim, deve concentrar no outro, no direito e na liberdade do outro. A liberdade do consumidor é que deve ser protegida, sua autonomia de vontade, racional e efetiva. São tempos de relações contratuais múltiplas, despersonalizadas e a durar no tempo e estender-se a toda uma cadeia de fornecedores de serviços e produtos. Tempos que impõem uma visão da obrigação como um processo muito mais complexo e duradouro do que uma simples prestação contratual, um dar e um fazer momentâneo entre parceiros contratuais teoricamente iguais, conhecidos e escolhidos livremente..$^{43}$

Segundo o emérito Professor de Filosofia do Direito da Universidade de Erlangen-Nürnberg, Reinhold Zippelius,o Direito deve ser um instrumento para uma contratos massificados, aquele que impõe

Revista da Faculdade de Direito da UFRGS, v. 15, 1998 
organização social justa e equilibrada (zweckmäßiger und gerechter Sozialgestaltung). ${ }^{44}$ Nesta visão, as normas jurídicas são, portanto, instrumentos que ajudam a determinar a realidade social, conforme os objetivos considerados justos e desejáveis para aquela sociedade. $O$ direito pode ser, portanto, um instrumento de justiça e inclusão social na sociedade atual, instrumento de proteção de determinados grupos na sociedade, de combate ao abuso do poder econômico e combate a toda a atuação dos profissionais que seja contrária a boa-fé no tráfico entre consumidores fornecedores no mercado.

Esta visão ativa e positiva do direito civil, como instrumento de combate aos males da sociedade atual através da imposição de um patamar superior de respeito e lealdade nas relações sociais, é possível no Brasil após o advento do Código de Defesa do Consumidor, como será a seguir analisada.

\section{B. Valorização da catividade, continuidade e da boa-fé nos contratos bancários}

Estes novos contratos complexos envolvendo fazeres na sociedade representam o novo desafio da teoria dos contratos. São serviços prestados por um fornecedor ou por uma cadeia de fornecedores solidários, organizados internamente, sem que o consumidor, na maioria das vezes, fique consciente desta organização. Tratam-se de serviços que no contexto da vida moderna, de grande insegurança e de indução através da publicidade massiva à necessidade

44. Zippelius, Reinhold, Rechstphilosophie, 3. Ed. Beck, Munique, 1994 p. 258. empresa fornecedora de serviços e os consumidores, notou-se que a ótica escolástica tradicional, de uma análise estática e unitemporal da relação obrigacional de exe cução diferida ou contínua não mais oferecia respostas adequadas. $\mathrm{O}$ lapso de tempo que se situa entre o nascimento da obrigação e o momento previsto para a satisfação da obrigação principal não pode mais ser visto como um "espaço vazio", ao longo do qual o devedor não é obrigado a qualquer comportamento particular, não se lhe impõe qualquer dever de conduta. Ao contrário, a relação obrigacional é um todo contínuo, onde desde o seu nascimento (e mesmo antes) as partes estão vinculadas por uma série de deveres anexos de conduta (Nebenpflichten), impostos, pelo princípio geral de boa-fé na execução das obrigações. Mesmo antes do vencimento ou da ocorrência do evento futuro e incerto, que dá ensejo à prestação principal, já estão as partes vinculadas a uma série de atos, de condutas gerais, instrumentais ou acessórias em relação ao adimplemento principal, condutas estas não menos importantes para o bom cumprimento das obrigações, para a realização dos interesses legítimos das partes do que a obrigação principal. ${ }^{45}$

Trata-se, portanto, de uma nova visão da obrigação, como um complexo de atos, condutas, deveres a prolongar-se no tempo, do nascimento à extinção do vínculo. Aceitar a existência de deveres de conduta anexos aos contratos, deveres anexos contratuais ou obrigações acessórias oriundas do princípio da boa-fé objetiva

45. Assim nosso livro sobre Contratos, 2. ed., p. 65

46. Veja Larenz, Karl, Lehrbuch des Schuidrechts, I, 14.Auff., Beck, Munique, 1987, p. 26 e seg. (como o dever de informar, de cooperar, dever de cuidado, de sigilo, de conselho, de lealdade etc.), significa reconhecer a imposição de um novo patamar de boa-fé no mercado, boa-fé criadora de deveres de conduta contratual. ${ }^{46}$

A noção de boa-fé objetiva, enquanto novo princípio a guiar a conduta dos contraentes nos contratos cativos significa uma nova e importante limitação ao exercício de direitos subjetivos. O exercício de um direito subjetivo, como o de estabelecer livremente o conteúdo e as cláusulas contratuais, será contrário à boa-fé (leia-se, abusivo) quando se utiliza para uma finalidade objetiva ou com uma função econômico-social distinta daquela para qual foi ele atribuído ao seu titular pelo ordenamento jurídico, como também quando se exercita este direito de maneira ou em circunstâncias desleais. O princípio da boa-fé objetiva, limitadora de direitos (= poderes) definirá um novo "grau" de abusividade das cláusulas e práticas comerciais presentes nos contratos oferecidos no mercado.

Para disciplinar tais relações contratuais complexas, cativas, de longa duração, passou-se, portanto, a uma visão dinâmica destes contratos massificados, de como sua especialidade e indiscutível importância social imprimem a necessidade de uma nova interpretação das obrigações assumidas, de uma visualização mais precisa da gama de deveres principais e secundários existentes nestas relações contratuais e de que, em virtude da confiança desperta- 
da, o paradigma máximo aqui há de ser o princípio da boa-fé objetiva.

Os contratos bancários atuais são contratos cativos de longa duração. Observadas as especialidades dos contratos bancários em questão, sob o signo da continuidade dos serviços, massificação $e$ catividade dos clientes, da prestabilidade por terceiros de serviços autorizados ou controlados pelo Estado, do macro-interesse do verdadeiro objeto contratual, da internacionalidade ou grande poder econômico dos fornecedores e, acima de tudo, continuidade das relações tendo em vista a essenciabilidade do crédito na sociedade de consumo atual, concluiu-se que os modelos tradicionais de contrato (contratos envolvendo obrigações de dar, imediatos e menos complexos) fornecem poucos instrumentos para regular estas longíssimas, reiteradas e complexas relações contratuais, necessitando, seja a intervenção regulamentadora do legislador através do CDC para a proteção dos mais vulneráveis, seja a intervenção reequilibradora e sábia do Judiciário nos casos concretos.

Frise-se, por fim, que no mundo atual a acessoriedade do crédito ao consumo atinge seu ponto máximo, a tal ponto de não mais discutir o direito ao acesso ao crédito, mas as discriminações através do cré-

Sobre os très novos temas citados, veja-se, por todos, Ramsay, lain e Willians, Toni, Inequality, Market Discrimination and Credi Market, in: Consumer Law in the Global Economy, Coord. lain Ramsay, Editor Ashagate/Dartmouth, Aldershot e Brookfield, USA, 1997, p. 233 e ség., em especial, p. 246.

48. Veja Calais-Auloy, Jean, Droit de la consommation, 3e ed., Dalloz, Paris, 1992, p.257.

49. Assim nosso artigo, Os contratos de crédito na legislação brasileira de Proteção ao consumidor, Revista Direito do Consumidor, vol. 17, pg. 40 .

50. assim L'Heureux, Nicole, Précis de Droit Commmercial, Presses de l'Université Laval, Québec, 1975, p. 226.

51. já em 1975 ,o Prof. Jean Calais-Auloy da Universidade de Montpellier chamou a atenção para a importância prática e teórica destas proibiçōes legais no que concerne os contratos de crédito, Calais-Auloy, J., Les cinq réformes qui rendraient le crédit moins dangereux pour les consommateurs, in: Recueil Dalloz, 1975, Chron..p. 21. caracterisada como função negativa, uma vez que ela reduz, limita a liberdade do elaborador do contrato de crédito e de suas renovações. Limita a liberade contratual (veja os arts. 39 e 51 do CDC), porque proíbe a transferência de certos riscos para os consumidores (veja a lista de cláusula abusivas do art. 51 do CDC). Aqui a intervenção do Estado nos negócios privados tem por objetivo alcançar um certo equilíbrio entre direitos e obrigações no texto contratual final, evitando a imposição de cláusulas desiquilibradoras, cláusulas de renúncia aos novos direitos dos consumidores ou mesmo a elaboração de novações contratuais eivvadas de abusos consolidados. Trata-se realmente de uma redução da liberdade de estabelecer livremente o texto do contrato de crédito. Esta nova limitação da autonomia da vontade tem também sua origem no princípio da boa-fé, ao evitar o abuso (art. 4, III e art. 51, IV) ou a vantagem exagerada do parceiro contratual preponderante (veja art. 4, III e art. 6, V do CDC).

\section{Relações contratuais fluídas e múltiplas: o problema da novação ou revisão contratual}

O CDC aporta realmente uma nova teoria ou visão contratual para o direito civil brasileiro, rejuvenescendo nossa doutrina e prática. Esta visão baseada na boa-fé objetiva das relações contratuais e em uma noção mais exigente de equilíbrio e

Sober a

Sobre a importância desta norma para atsar no abusividades nas relaçōes bancárias em relaçăo a consumidores, veja a Almedina, Coimbra, 1998, p. 437 e seg. equidade contratual impõe um novo regime para os contratos cativos de longa du ração e proibe uma série de práticas agora consideradas abusivas. Dentre estas práti cas e cláusulas consideradas abusivas está de modificar unilateralmente o conteúdo do contrato, das prestações, da qualidade (art. 51, XIII do CDC), a de modificar unilate ralmente o preço ou valor pago em contra prestação de serviços ou produtos (art. 51 $\mathrm{X}$ do CDC), que imponham a conclusão de outro negócio jurídico -através de represen tante - pelo consumidor (art. 51, VIII do CDC) e, de modo genérico, a de estabele cer "obrigações consideradas iníquas, abusivas, que coloquem o consumidor em desvantagem exagerada, ou sejam incom patíveis com a boa-fé ou a equidade". (ar 51, IV do CDC) ${ }^{52}$, assim como a de impo em contrato de consumo, geralmente ela borado unilateralmente, cláusulas que im pliquem renúncia ou disposição de direito (art. 51,I do CDC) e que estejam em desa cordo com o sistema de proteção do con sumidor (art. 51, XV do CDC).

Em outras palavras, o novo regime dos contratos bancários de consumo impede que o elaborador unilateral dos contratos abuse de sua posição contratual (Machtposition) e aproveite-se do desequelíbrio intrínseco e estrutural destas relações para impor cláusulas abusivas ou contrárias a leis imperativas vigentes e após, mesmo, renove estas relações continuadas : por natureza, em virtude da expectativa de contínuo acesso ao crédito e rolagem eventual da dívida.

$$
\text { Almedina, Coimbra, 1998, p. } 437 \text { e seg. }
$$


Neste sentido merece nossa especial atenção uma prática bancária existente desde 1993, coincidente com a jurisprudência mais ativa de defesa do consumidor dos Tribunais estaduais. Tendo em vista esta aplicação prática do CDC, os bancos e instituições de crédito passaram a propor a seus clientes uma renegociação "sanadora" ou novação "salvadora" da dívida, a qual além de consolidar a dívida pendente baseada em juros acima do patamar constitucional e da cobrança reiterada e cumulativa de juros sobre juros e outras práticas reiteradamente consideradas abusivas, retirava do novo texto contratual todos os abusos identificados como tais na jurisprudência e nas novas leis, incluindo ai o CDC, "adaptando" pois esta relação continuada aos novos patamares de boa-fé e equilíbrio de prestações exigido por lei, mas perenizando o abuso no débito consolidado, confessado ou renovado na renegociação.

Trata-se, pois, de uma prática comercial abusiva do setor bancário, a qual visa ou consegue justamente fraudar o efeito das normas do Código de Defesa do Consumidor, da limitação constitucional dos juros e de outras leis imperativas através da novação da dívida, isto é, do pagamento e fim teórico da relação abusiva e "nascimento" de uma nova relação "sanada" dos vícios da primeira, mas que traz em seus encargos financeiros os frutos do abuso já cometido e "sanado" pela manifestação de vontade do consumidor em novo contrato ou na renegociação. Há nesta "nova contratação" o cuidado de incluir na relação de consumo apenas cláusulas contratualmente lícitas, segundo a jurisprudência

majoritária e normas especiais em vigor, inclusive o CDC.

Através da teoria contratual normal a solução para este problema não é da mais fáceis, pois que o contrato chegou a seu fim, seu bom fim, que é o ádimplemento através da novação, da confissão de dívida ou da renegociação contratual. Teoricamente o primeiro contrato foi extinto. Como propor um exame judicial do conteúdo de um contrato extinto ? Parece-me que aqui há de se avançar e aprofundar a análise, pois somente a aceitação de uma espécie nova de pós-eficácia dos contratos, baseada na boa-fé necessária às relações de consumo, pode propor uma solução para este problema prático de enrequecimento sem causa lícita. $\mathrm{O}$ exame judicial do conteúdo do contrato extinto é possível, justamente através da nova visão continuada e de longa duração das relações de consumo, que compõe-se de vários e múltiplos contratos, de contratos acessórios e principais, contratos iniciais e finais, de cadeias de fornecedores solidários por lei em virtude justamente dos laços que formam a catividade de seus clientes, fornecedores e consumidores entrelaçados em relações contratuais complexas de consumo, múltiplas e fluídas que são o novo desfaio de nosso tempo. Vejamos, pois, duas análises destes contratos cativos de longa duração.

\section{A. Contratos Bancários como contratos relacionais?}

O realismo norte-americano $0^{53}$ denominou estas relações e contratos de

53. Assim Oechsler, Jürgen, Wille und Vertrauen im privaten Austauschvertrag, in RabelsZ 60 (1996), p. 92.

Revista da Faculdade de Direito da UFRGS, v. 15, 1998

"relacionais" (relational contracts) ${ }^{54}$, destacando os elementos sociológicos que condicionam o nascimento e a estabilidade dos contratos complexos de longa duração. A contribuição destes estudos, que remontam a 1974 , foi grande, pois observando as relações "não-contratuais", as projeções de troca dos empresários e sua organização em networks, baseadas mais na confiança, solidariedade e cooperação no que em vínculos contratuais expressos, desenvolveu a noção de um contrato aberto, de uma relação contínua, duradora ao mesmo tempo em que modificável pelos usos e costumes ali desenvolvidos e pelas atuais necessidades das partes..$^{55}$

$O$ potencial deste modelo de pensamento contratual é fascinante. Identificar um contrato relacional onde há vinculo, mas não necessariamente contratual, como nas parcerias econômicas furtivas e momen tâneas de hoje. Identificar um contrato relacional, onde o vínculo oficialmente já acabou, mas há relacionamento a posterior, como em um contrato cumprido, não renovado, mas novado ou mesmo reescri to. Identificar um contrato relacional onde existem vários contratos, com várias e diferentes pessoas jurídicas, como os contratos com bancos múltiplos, 6 contratos em um

54. O iniciador desta teoria foi lan Macneil,veja Macneil,p. 691 e seg. Veja também seus outros artigos: Contracts: Adjustement to Long-Term Economic Relations Under Classical, Neoclassical, and Relational Contract Law, in Northwestern U.L.Rev. (1977/78), 854ss; Values in Contract: Internal and External, in Northwestern U.L. 78(1983), 340ss., Relational Contract: What We Do and Do not know, in Wis. L. Rev. 1985, 483ss.

55. Veja a adaptação desta doutrina para o Brasil, em Macedo,Ronaldo Porto Jr., Sociologia Juridica e Teoria do Direito: A teoria relacional e a experiência contratual, Tese de Doutorado USP, São Paulo, 1997, p. 127 e seg.

56. Assim Oechsler, $p$. 93. Especial dificuldade apresenta a doutrina da "Consideration" na conclusão de renegociaçōes ou modificaçōes contratuais não formais.

57. O sistema do $\operatorname{CDC}$, que será analisado mais adiante, segue esta linha não solene e ainda a amplia nos artigos 30,34 e 48 incluindo toda e qualquer informação na relação contratual de consumo. Sobre o sistema continental europeu, veja Oechster, $\mathrm{p}$. 109ss. só, ou um contrato com 4 pessoas diferentes, banco, corretora, financeira, segurado ra, ou fornecedora de serviços outros, tudo em um só relacionamento finalístico de consumo! Identificar um contrato de troca real há na teoria um contrato unilatera clássico, como no mútuo, destacando a re com que o nexo (Finalnexus) que liga a prestação oficialmente única e a contra-prestação escondida (pagamento de juros pelo capital colocado a disposição e o tempo) reapareça, criando um sinalagma fantasma, a clássica.

Note-se, porém, que este modelo contratual foi criado em virtude de dificuldades específicas e imanentes ao sistema da commom law com as relações de longa du ação. ${ }^{56}$ Estas dificuldades de englobar $n$ contratual as promessas e informa ços não formais ou não escritas, de preen interpretação integrativa pelo Judiciário são menores em um sistema contratual não solene como o brasileiro ou o continental europeu.$^{57}$ Os demais problemas apresentados podem ser solucionados, no direito brasi-

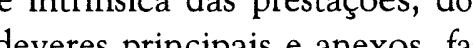


leiro, pelos princípios da confiança, da boafé, da acessoriedade das relações de préconsumo ou pela teoria da aparência. ${ }^{58}$

Sendo assim, a mais importante contribuição destes estudos para a nova teoria contratual brasileira é a criação de um modelo teórico contínuo que engloba as constantes renegociações e as novas promessas, bem destacando que a situação externa e interna de catividade e interdependência dos contratantes faz com que as revisões, novações ou renegociações contratuais naturalmente continuem ou perenizem a relação de consumo, não podendo estas, porém, autorizar abusos da posição contratual dominante, ou -pior-validar prejuízos sem causa ao contratante mais fraco ou tentar superar e descumprir deveres de cooperação, de solidariedade e de lealdade que integram a relação em toda a sua duração. ${ }^{59}$

Em resumo, a teoria do contrato relacional pode contribuir, especialmente nos contratos de mútuo e em geral de fornecimento de serviços, para uma nova compreensão da confiança despertada pela atividade dos fornecedores e para a aceitação de uma readaptação constante das relações de longa duração de forma a não frustar as expectativas legítimas das partes, apesar da limitada da vontade manifestada inicialmente. ${ }^{60}$

\section{B. Relações continuadas e novação contratual nos contratos bancários}

Apoiados em cláusula específica nos contratos e pela contigência nacional de insolvência e falta de crédito, os bancos brasileiros ofereceram aos consumidores desde 1993 uma revisão contratual "sanadora" e novação da dívida, na qual seriam retiradas dos contratos renegociados a previsão de cobrança de juros reais (juros remuneratórios) superiores a $1 \%$ ao mês e outras cláusulas consideradas abusivas na jurisprudência e em leis imperativas, como o próprio CDC. Ficava ali, porém, consolidada e confessa a dívida oriunda de anos de cobrança destes juros exagerados, cumulação de taxas, multas, capitalização mensal e outros abusos.

A cláusula, que permite a renegociação bilateral benéfica ao consumidor, nada tem de abusiva, ao contrário, procura melhorar e adaptar os contratos de consumo às regras existentes no ordenamento jurídico naquele momento. Infelizmente, a sua prática no mercado brasileiro foi perversa. Perversa, pois criou expectativas no consumidor que se iria na revisão "excluir" e "retirar" as cláusulas abusivas de cobrança de juros usurários ou mesmo juros sobre juros. Acabou, porém,

58. Segundo Oechster, p. 114, a teoria do contrato relacional é uma "re-importação" do modelo jurílico alemão. A solução alemã baseada na responsabilidade pela confiança teria sido recebida nos EUA justamente para suprir os problemas da common law baseada na responsabilidade pela confiança teria sido recebida nos EUA justamente para suprir os problemas da common law com relaçōes de longa duração e que agora, estaria retona do ao conthente. A pitura do onginal de Macneil, ao contrário, parece partir de observaçōes básicas sociológicas, quanto às rázes do contrato, para só então aprofundar-se na relação de
confiança, veja Macneil, p. $701 \mathrm{ss}$ em especial.

59. Como ensina Macedo, Relacional, p. 335 , a teoria contratual relacional tem função descritiva, analítica, mas „o modelo relacional tem também caráter normativo e prescritivo. Assim é que ele recomenda uma revalorização e ampliação do uso do princípio da boa-fé, justiça e equilíbrio contratual como princípios capazes de orientar os agentes contratuais e operadores do direito na direção do reconhecimento das circunstâncias fáticas concretas."

60. Assim também conclui Oechster, p. 117ss.

Revista da Faculdade de Direito da UFRGS, v. 15, 1998

preservando o abuso, consolidando-o em imensas e impagáveis dívidas. Perversa, pois ao retirar do contrato atual as cláusulas abusivas, ao impor ao consumidor que confessasse a dívida oriunda do abuso, quase impossibilitou a atuação reequilibradora do Judiciário. Geralmente os fornecedores exigiram a assinatura de confissão de dívida total ou assinatura de títulos de crédito, preservando os juros já cobrados e o passivo deles resultantes já existente, em ficta declaração que o pagamento era devido, para só então elaborar a novação contratual, agora, sim, sem as cláusulas abusivas e em texto uniforme pré-elaborado unilateralmente.

Em outras palavras, os débitos e encargos resultantes de cláusulas tão abusivas que foram retiradas pelos próprios Bancos e agentes financeiros na renegociação, encargos contrários à boa-fé, mesmo assim foram cobrados e foram incluídos no passivo, no total da dívida. Este total foi transportado para a renegociação, assinada confissão ou título executivo extrajudicial pelo total da dívida e apenas as cláusulas foram retiradas do texto, não seus efeitos abusivos já ocorridos.

Esta atitude quase paralizou o controle do Judiciário brasileiro, pois na rela- ção de consumo atual o contrato não mais apresentava as referidas cláusulas abusivas, a prestação inicial (débito) fora paga por novação e o dever de adaptar seus contratos ao CDC já teria sido cumprido. A defesa dos Bancos era simples, afirmando que adaptara seu contrato e que não cobrava tais juros usurários ou praticava anatocismo. Meia verdade quase destruidora, pois o controle do conteúdo dos contratos não é só atual, mas sim desde o início da relação contratual de consumo, relação continuada vista como um processo finalístico, como uma relação de deveres mútuos de conduta, de boa-fé e de prestação, que se prolonga no tempo até atingir o seu fim: o bom cumprimento do objetivo inicial do contrato e das expectativas legítimas (somente as legítimas) de ambos os contratantes. No caso concreto, abusiva foi a cobrança durante anos de encargos baseados ou sustentados por cláusulas consideradas por lei (Constituição e CDC) e por jurisprudência pacífica como abusivas e/ou lesionárias.

A jurisprudência gaúcha respondeu a esta renegociação contratual prejudicial ou revisão abusiva de forma clara. Considerou viável a revisão e o controle do conteúdo de toda a relação, em suas várias fases e contratos renegociados. ${ }^{61} \mathrm{~A}$ relação é efeti-

61. Bom exemplo desta linha jurisprudencial são as decisões, ainda não publicadas, do TARGS, com as seguintes ementas: „Titulo Executivo Extrajudicial - Ação Declaratória Revisional de Contratos - Renegociação. Viável a revisão de toda relação negocial, haja vista ser verificável no contrato de renegociação a incidência de encargos excessivos, o que, por certo, se repetiu nos contratos renegociados. - Art. 42, Parágráfo Único do CDC - Não há que se falar em quantia indevida, uma vez que o contrato foi livremente firmado, incidindo os encargos contratuais. 0 que ocorre é a abusividade das cláusulas contratuais... 0 índice mais favorável à recorrente é o IGP-M, devendo este 0 adotado... Não caracterizada a mora, iniviável a cobrança de multa contratual. - Juros Remuneratórios. Quer pela auto-aplicabilidade da norma constitucional, ou pela legislaçäo infraconstitucional, os juros ...- Juros Remuneratơrios. Quer pela auto-aplicabilidade da norma consitucional, ou pela legislaçáo infraconstitucional, os juros $5^{\mathrm{a}}$ C. TARGS, j. 05.09.96, Rel. Juiz Jasson Torres ). "Embargos à execução - Instrumento particular de confissão de dívida e

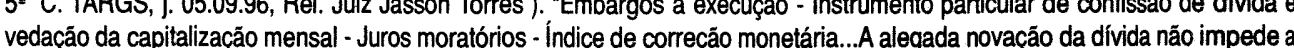
vedaçáo da capitalizaçāo mensal - Jưos moratórios - Indice de correção monetária....A alegada novaçăo da dívida náo impede a revisáo de toda a contrataçáo entre aspa
Rel. Juiz Manuela Martinez Lucas). 
vamente continuada ${ }^{62}$, é um contrato cativo de longa duração, em que o consumidor, na prática, aceitará qualquer renegociação, mesmo que abusiva ou a ele extremamente prejudical para que não vençam antecipadamente seus débitos e tenha tempo de cumprir sua prestação.

No caso, a renegociação nunca poderia ser negada, pois era sanadora de um dos grandes problemas destas relações econômicas: o preço do crédito, o custo do serviço bancário no Brasil. O que há é impossibilidade jurídica de sanar a nulidade ou ilegalidade por novo acordo, por confissão de dívida ou renegociação das obrigações. ${ }^{63}$ As cláusulas antigas eram abusivas, tanto que foram retiradas, logo, esta abusividade e devem ser retirados da relação adpatando-a à ordem jurídica então vigente. ${ }^{64}$

Mister se faz a declaração da abusividade das cláusulas pretéritas, para sanar a relação, reequilibrando-a, declarando-se, por conseguinte, indevidos os encargos e ônus resultantes destas cláusulas abusivas nulas, de efeitos sempre presentes. É cabível a repetição do indébito. ${ }^{65}$ Note-se que a nulidade da cláusula pelo CDC é absoluta, logo, retroage, tornando ilícita a cobrança realizada e diminuindo a dívida atual do consumidor. ${ }^{66}$ Não havenseus efeitos também estão contaminados por

62. Assim a jurisprudência majoritária da $4^{\mathrm{a}}$ Câmara Cível do TARGS, como se observa nas seguintes emendas: "Contratos Bancários- Revisão. É cabível a revisão de todos os contratos, mesmo consolidados em renegociação de débito. Relaçōes negociaciais que constituem uma situação jurídica continuativa que deve ser encarada como uma unidade...."(Ap. C. 196104160, Rel. Juiz Moacir Leopoldo Hasser); "Revisão de Contrato - Confissão de Dívida. A confissão de dívida não impede a revisão do débito nas relaçōes jurídicas continuativas, adequando-se à ordem jurílica. Limite de juros e sua capitalização. Juros de mora e multa. Correção monetária e comissão de permanência. Sunstituição da TR pelo INPC: jurisprudência do STJ.“ (Ap. C. 196088041, Rel. Juiz Moacir Leopoldo Hasser).

63. Veja decisão, ainda não publicada, do TARGS em relação inter-empresarial, mas que no mérito pode servir como exemplo: "Ação Revisional de Contratos Bancários e Repetição de Indébito e/ou compensação. Possibilidade de revisão: relação juríica

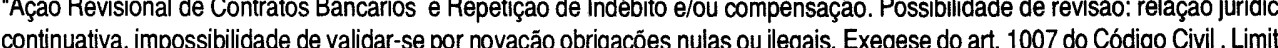
continuativa. impossibilidade de valldar-se por novaçao obrigaç̧es nulas ou legalis. Exegese do art. 1007 do Código Civil . Limite legal de juros e sua capitalizaçāo. distinçāo entre juros remuneratorios e juros moratórios. Elevação da taxa pelo inadimplemento. Correção monetária. Sucumbencia. Provimento parcial do primeiro e integral do segundo apelo.")..."( Ap.Civ. $196121811,4 a$ C.
TARGS, i. 20.02.97, Rel. Juiz Moacir Leopoldo Haeser ).

64. Assim decisão da 4a Câmara Cível do TARGS: "Revisão Contratual - Cabimento. Cabe a revisão dos contratos bancários para adequação de suas cláusulas à ordem jurídica, em especial no tocante à taxa de juros e sua capitalização. Precendentes da Câmara e do Superior Tribunal de Justiça. Extensão da revisão: relaçăo jurídica continuativa."( Ap.C. 196089858, Rel. Juiz Moacir Leopoldo Hasser).

65. Assim a decisăo do TARGS, em relaçăo inter-empresarial de leasing, em que forte no art. 29 se aplicou o CDC: „Repetiçáo do Indébito. Aplicação do CDC para a hipótese de considerar Erro - Caso de nulidade absoluta. É cabível a repetição do indébito em Indébilo. Aplicaçáo do CDC para a hipolese de considerar Ero-Caso de nulidade absoluta. É cabivel a epelçáo do indebilo em contratos ja quitados. Quem cobra juros acima de $12 \%$ viola expressa disposiçăo de lei. Logo, náo há erro(defeito do ato anulável), mas ilicito (defeito do ato nulo). Ademais, mesmo que se considere erro, incide o Codigo de Defesa do Consumidor, inversão do ônus da prova. Assim não cabe ao devedor provar que pagou com erro, para repetir o indébito, e à instituição financeira que incube demonstrar que cobrou com acerto. Logo, é a instituição financeira quem deve provar que náo houve erro. Voto vencido. Apelaçăo desprovida. ")..."( Ap.Civ. 196246 151, 5a C. TARGS, j. 12.06.97, Rel. Juiz Rui Portanova ).

66. Note-se que mesmo se a nulidade imposta pelo $\mathrm{CDC}$ fosse ad argumentandum relativa, não teria sido sanada pelo novo acordo, porque também contrato de adesão, segundo o art. 54 do CDC, não se presumindo pois que o interessado (prejudicado), 0 consumidor, com ela tenha concordado efetivamente, se entrou com ação específica em contrário para rever o texto e retirar da relação continuada os efeitos dos abusos antes cometidos. Frise-se que a nulidade imposta pelo CDC é absoluta, até mesmo porque os direitos assegurados no Código são indisponíveis, uma vez que o $C D C$ é norma de ordem pública (art. 1 do $C D C$ ), não prevalecendo sobre eles os acordos e contratos particulares.

Revista da Faculdade de Direito da UFRGS, v. 15, 1998 to mais "causa" para a cobrança de juros executada, reduz-se a dívida, e o pagamento indevido deve ser devolvido. Descabe exigir-se a prova do pagamento errado, como previa o art. 965 do $\mathrm{CCBr}$., pois no sistema do CDC, é dever e risco profissional do fornecedor cobrar corretamente $e$ segundo lhe permitem as normas jurídicas imperativas (vide art. 42, parágrafo único do $\mathrm{CDC}) .{ }^{67}$

A alegada novação da dívida não impede a revisão de toda a contratação entre as partes, se esta contém ou continha cláusulas nulas. O controle do conteúdo da relação de consumo contratual autorizado pelo CDC se mostra possível mesmo com o contrato findo, segundo a jurisprudência ${ }^{68}$, pois absoluta a nulidade ${ }^{69}$ e (pós) eficaz o paradigma da boa-fé. Note-se aqui força do princípio da boa-fé objetiva no novo direito dos contratos, força que permite, ao exemplo da pós-eficácia dos deveres anexos (de sigilo, de cooperação, de cuidado e de não-concorrência), uma pós-eficácia do controle do sinalagma inicial (!), do equilíbrio econômico da relação e da licitude destas cobranças abusivas, mesmo quitado o contrato, realizado - teoricamente- o seu fim principal.

A cláusula e a prática em contratos de adesão que permite a renegociação pre judicial ao consumidor, a revisão contratual abusiva de forma a fraudar o controle do conteúdo da relação contratual continuada é contrária à boa-fé e a lealdade normal entre parceiros contratuais reiterados. Se válida fosse, seria figura próxima a fraude à lei, pois traz um véu de "legalidade" a uma relação contínua que por anos sofreu o impacto da abusividade das cláusulas principais. Esta renegociação, esta revisão contratual, autorizada em cláusula e mesmo que consensual, não pode ter como efeito sanar a nulidade absoluta imposta pelo CDC em seus art. 51 e seguintes. Não há como, por manifestação de vontade das partes, mesmo que teoricamente livre, escapar ao controle e ao patamar mínimo de boa-fé e equilíbrio imposto imperativamente pelo CDC. Esta também é a lógica do Projeto de Código Civil de 1984 quando em matéria de novação expressamente dispõe que: "Não podem ser objeto de novação obrigações nulas" (art. 366 do Projeto 118/ 84). $O$ absolutamente nulo não se sana por vontade das partes !

Ainda quanto ao Projeto de Código Civil de 1984 deve ser também analisado um outro aspecto, pois que este projeto

67. Assim concorda Benjamin, Forense, $3^{2}$ Ed., p. 248-249

68. No voto vencido da decisão antes mencionada defendia o Relator inicial Juiz Márcio Borges Fortes que "a revisáo de cláusulas contratuais só se mostra possível quando ainda em curso o contrato", sendo Mntõio Borges Fortes que "a revisáo de cláusulas na inicial, por absoluta impossibilidade jurídica do pedido." "Voto do relaror vencido, p. 3 e 4 do cedodo acórdáo Ap Civ deduzic 151, $5^{\mathrm{a}} \mathrm{C}$. TARGS, j. 12.06.97, Rel. Juiz Rui Portanova ).

69. Assim o Relator vencedor no réérido acórdáo: „Cobrar juros acima de $12 \%$ é ato com objeto ilicito, pois afronta texto expresso de ei. Logo e ato nulo (invalido)....esta Câmara tem aceitado, sem qualquer dissonância, a revisăo ( $\Theta$ por consequiência o abatimenSei, o presentes os contratos subseqüentes quitam os conseqüentes. feito em dinheito Aleiñó rente. Naquelas hipóteses o pagamento do contrato dá-se por via da novaçáo. Aqui o pagamento fol feito em dinheito. Alei náo restringe forma de pagamento, para a imposição do indébito...não cabe ao julgador restringir.... Voto do Relator, p. 6, Ap.Civ. 196246 151, 5 C. TARGS, j. 12.06.97, Rel. Juiz Rui Portanova).

Revista da Faculdade de Direito da UFRGS, v. 15, 1998 
legislativo positiva a figura da lesão, valorizando - pelo menos a primeira vista - o mencionado estado de "premência", de "necessidade", de "inexperiência" que acabam por levar ao consumidor a aceitar "prestação manifestamente desproporcional" (art. 156 do Projeto 118/84). Este paradigma da lesão, parece-me, data vênia, porém, não ser o melhor, pois remete a uma consideração econômica e não moral da divída consolidada na novação "sanadora". Note-se igualmente que a lesão positivada no Projeto de 1984, em seu texto aprovado pelo Senado, não é o referido paradigma de equilíbrio geral, mas sim um vício da vontade, vontade esta privada revisitada e revalorizada. Sendo assim a lesão pelo Projeto de novo Código Civil será sancionada somente com a nulidade relativa (art. 177, II), como um outro vício da vontade.

Penso que no caso em exame não há vício da vontade, mas vontade em espaço não mais reservado para a autonomia de vontade, vontade limitada por novos paradigmas legais, pois não há mais espaço para o auto-regramento privado através de cláusulas consideradas abusivas pelo CDC: justamente por ser de ordem pública a norma do CDC, logo, indisponível pela vontade das partes. A ratio no CDC é a proteção da vontade do consumidor, limitando também o seu poder de auto-submissão ao outro co-contratante, visualizando de forma bastante realista que assim como o consumidor aceitou sem discutir o primeiro texto contratual por adesão, aceitará também o da renegociação ou da novação, mas que ex vi lege nenhum dos dois pode conter abusos ou autorizar práticas contrárias ao novo patamar de boa-fé nas relações de consumo. ${ }^{70}$

Sem querer trazer uma conclusão stricto sensu a tema tão novo e polêmico como o aqui exposto, gostaria de frisar, por fim, que face à realidade atual impõe-se pensar as relações bancárias múltiplas atuais e pós-modernas como contratos cativos de longa duração submetidos ao novo regime contratual do CDC, sempre que o outro co-contratante for um consumidor. As operações bancárias, os contratos oferecidos no mercado brasileiro, envolvendo serviços e produtos, dentre eles o crédito, estão regidos pelas regras gerais sobre contratos $\mathrm{e}$ pelas regras especiais do CDC, em caso de contratos bancários de consumo. As relações contratuais bancárias são múltiplas e complexas e visualizadas hoje, como formadas por um feixe de deveres principais e anexos negociais, e de deveres de informação, e de lealdade pré- e pós-negocial, isto é, de "vinculações extranegociais"71 e negociais que se prolongam no tempo a sujeitar os contraentes a deveres indisponíveis.

70. Assim pondera o Juiz Carlos Alberto Alves Marques na referida Ap.Civ. 196246 151, $5^{\mathrm{a}}$ C. TARGS, j. 12.06.97, Rel. Juiz Rui Portanova, p. 6: "...tratando-se de contrato de adesăao, não é ao devedor que incube provar ter pago com erro, para repetir o indébito, é ao Banco que cabe demonstrar ter cobrado com acerto, para inviabilizar a pretensão.... pe fato, não há como negar que os contratos bancários, como o questionado, são de adesão, já que as instituiçōes bancárias os apresentam prontos, segundo as diretrizes da orientação macroeconômica vigorantes, legais ou não, constitucionais ou não, sem que o cliente possa discutiri suas cláusulas, tal como está no art. 54, do CDC, que se aplica aos serviços bancários, financeiros e de crédito, como, com evidente clareza, consagra o $\$ 2^{2}$, do art. $3^{\circ}$, da dita lei."

71. Menezes Cordeiro, pg. 24, citando ensinamentos de Canaris, in Bankvertragsrecht, vol. 1.

Há, efetivamente, uma nova geração de contratos de consumo de massa, a qua demonstra uma importância renovada ( mesmo avassaladora) na prática jurisprudencial atual e que estamos aqu denominando de pós-moderna ou de "contrato cativo de longa duração", mas que tam bém pode ser considerada "relacional", se assim preferirem. Mais importante do que acrescentar uma nova denominação a es tes novos e velhos contratos, hoje, comple xos é identificar esta nova prática e os desafios propostos por estas relações contratuais em cadeia, fluídas, complexas, solidárias, múltiplas, formalmente desconectadas, mas intrinsicamente aces sórias ao consumo e que reduzem a uma imprescionante posição de catividade e de extrema vulnerabilidade técnica e jurídica o leigo, o consumidor. Do civilista atual es perasse possam contribuir seus estudos para o desenvolvimento de uma nova linha de pensamento, assentada nas figuras, conceitos e direitos da antiga dogmática do sécu lo XIX, mas que seja capaz de resolver os problemas práticos do dia a dia desta nossa complexa e momentosa vida em sociedade e do desafiante mercado atual. $O$ direito privado deve ser um instrumento de Justiça e de equilíbrio das relações, a criar harmonia em sociedade e a incentivar 0 tratamento leal e de boa-fé entre todos e não um instrumento para perenizar abusos consolidar desequilibrios contratuais continuados. 


\section{Projeto do Código Civil - A Importância das Cláusulas Gerais na Regulação do Direito Pessoal e
Patrimonial de Família'}

Eduardo Ofilva da Oilua

Mestrando em Direito na Universidade Federal do Rio Grande do Sul - UFRGS

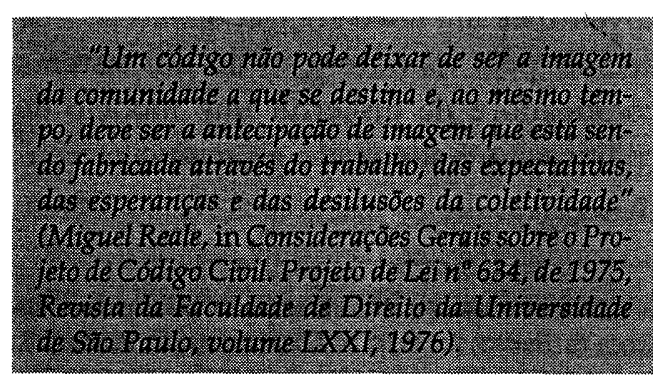

\section{SUMÁRIO}

Introdução.

Parte I - Estrutura do Direito de Familia no Projeto do Código Civil:

A) Direito pessoal e patrimonial de familia;

B) Cláusula geral da comunhão plena de vida e suas repercussões.

Parte II - Elementos de cisão e ressistematização do Direito de Família:

A) O Direito de Família como um modelo aberto;

B) Inter-relações sistêmicas. Apontamentos conclusivos.

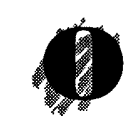

tema que iremos abordar revestese de especial importância em face da votação, pelo Senado Federal, do Projeto de Código Civil em tramitação desde $1975 .{ }^{2}$ No que concerne especificamente ao Direito de Família, sua elaboração, de ares inovadores e ousados para época, garante ainda hoje surpreendente atualidade em comparação aos mais modernos ordenamentos jurídicos contemporâneos e a permanente evolução cultural acerca des. ta matéria. Da lavra do Professor Clóvis do Couto e Silva, falecido em 1992, Professor Catedrático de Direito Civil da Universidade Federal do Rio Grande do Sul, civilista reconhecido internacionalmente por sua visão peculiar do Direito, o livro de Direito de Família pôde auto-renovar-se através do

1. Trabalho realizado na disciplina Teoria Geral do Direito Privado, sob a orientaçăo da Professora Doutora Judith MartinsCosta.

2. A comissáo que elaborou o projeto de Código Civil foi coordenada pelo Professor Miguel Reale e era composta também por José Carlos Moreira Alves, Agostinho de Arruda Alvim, Sylvio Marcondes, Ebert Vianna Chamoun $\Theta$ Torquato Castro. Tratava-se do Projeto de Lei $n^{2} 634 / 75$ no Senado Castro. T
Federal. 